\title{
Ecological problems of the Russian coast of the south gulf of Finland
}

\author{
Olga Vitjazeva ${ }^{1, *}$, Igor Kozhuhov ${ }^{1}$, and Larisa Naumova ${ }^{1}$ \\ ${ }^{1}$ Admiral Makarov State Univercity of Maritime and Inland Shipping 5/7 Dvinskaya Str., St. \\ Petersburg 198035, Russian Federation
}

\begin{abstract}
The present work is an analytical review of the operating characteristics of the southern coast of the Gulf of Finland, which makes it possible to assess its state from the point of view of ecology. As a geographical and social object, this natural ecosystem can be reasonably included in the list of areas of potential ecological risk. This is due to active fishing activities and the development of sea cargo transshipment complexes in this area, taking into account the territorial advantages of local harbors. We believe that, with further accumulation of factual material, it will, with sufficient probability, determine the trends in the further development of this ecosystem. In the proposed work, the kinematics of coastal water flows near the southern coast was investigated as a factor contributing to the distribution of harmful impurities along the open part of the coast. Heavy metals and petroleum hydrocarbons were selected here as indicator pollutants. At the same time, the article does not consider in detail the issues of the influence of specific sources of pollution on the state of the ecosystem as a whole. The meaning of its writing, as planned, is to find a correlation between the pollution scheme of a given coast and the natural specifics of the local hydrological regime. When writing the article, the basis for the analytical study was the factual material that was once obtained by the forces of the Maritime Academy in the process of performing coastal field work at this facility. Further, the article contains the results of hydrochemical and geochemical testing of natural waters and modern bottom sediments of the Gulf, borrowed from domestic and foreign sources.
\end{abstract}

\section{Introduction}

The southern part of the coast of the Gulf of Finland, which is under the jurisdiction of the Russian Federation, has significant production capacities that can, to one degree or another, have a negative impact on the environment. In this regard, the work on the construction of the port of Ust-Luga in the Luga Bay, which was inevitably accompanied by a mechanical type of pollution of the surrounding water space, deserves attention. The further operation of the new port is no less important. Further, it's necessary to mention the regular discharge of water from the cooling circuit of the Leningrad nuclear power plant in the Koporsky Bay. It is also good to pay attention to the radioactive contamination of the

\footnotetext{
*Corresponding author: vitjazeva_olga@mail.ru
} 
coast as a result of the passage of the "Chernobyl cloud" over the areas of Luga Bay and Narva Bay $\left({ }^{137} \mathrm{Cs}\right.$ activity). Finally, we must not forget about the biological form of pollution of the bay due to the intake of phosphorus, which once led to the abnormal development of blue-green algae in the reservoir.

It is known that with the transfer of water masses, harmful substances are also involved in the processes of further migration with their subsequent accumulation in certain places. Contaminants released in this way must inevitably be incorporated into local food chain systems.

The coastal area under consideration begins at the Russian-Estonian border (near the Karostel point) and ends in the area of the Bolshaya Izhora settlement, at the root of the dam's protective structures - CPS (fig. 1).

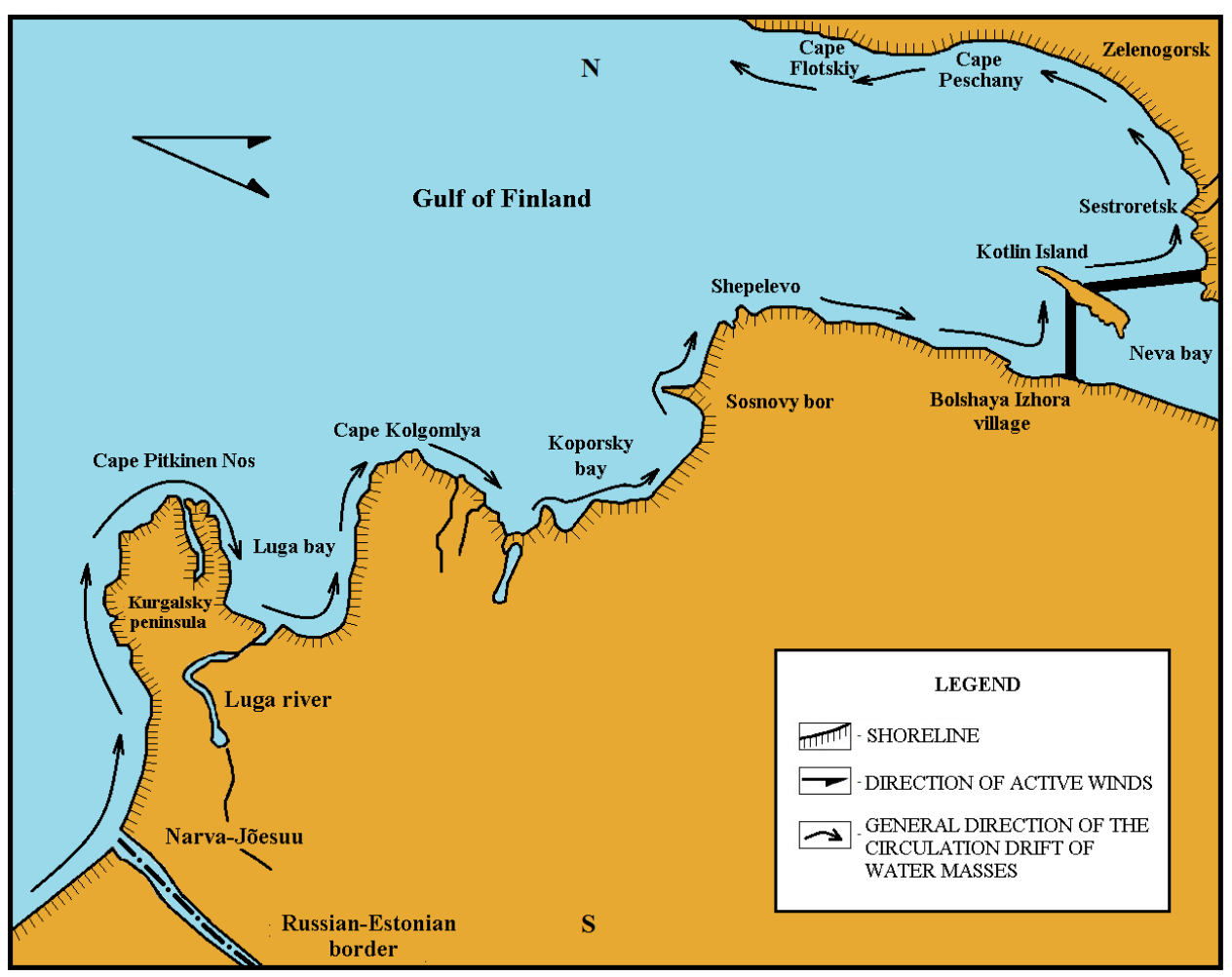

Fig. 1. Eastern part of the coast of the Gulf of Finland (classical scheme of water mass drift for large bodies of water in the northern hemisphere).

When considering the designated coastal contour, attention is drawn to the fact of the diversity of landscape characteristics at a fairly short distance. According to its external features, the southern coast can be subdivided into three independent sections. The criterion for such delimitation is primarily the exposure of the coastline in relation to the cardinal points and its very configuration.

As the first relatively autonomous section of the coastal strip, it is possible to distinguish an area of a slightly concave coast, close in type to a rectilinear one. It covers the lateral, eastern part of the coastal contour of Narva Bay. The marked border section of the coast is oriented strictly to the west. As the so-called "dangerous" winds capable of creating a significant wave-forming effect, the winds of the western, north-western and northern quarters prevail in this place, with a wave acceleration distance that is quite solid for a real reservoir. Let's call this section the western one. 
Moving further, eastward from Pitkinen Nos cape, one can observe a significant change in the general pattern of the coastline with a sharp turn to the northwest. The new section of the coast is significantly different in appearance from the previous one. In this case, we are talking about the coasts of the bay type. Luga and Koporsky Bays protrude deeply into the land. This site will be considered central.

The next part of the coast, geographically closest to St. Petersburg, is located in the eastern side of the Gulf of Finland - from Cape Shepelevsky to the Bolshaya Izhora settlement. The last, northeastern, section is oriented northeast. A little further, beyond Bolshaya Izhora, the open shore line joins with the base of the western wing of the Complex of protective structures (CPS). This is where the object considered in the article ends [1].

\section{Methods and Materials}

In the process of working on the article, many years of observations by the State Meteorological Service (SMS) concerning this object were used as a source material. We are talking about the wind regime and hydrological characteristics of the southern coast of the Gulf of Finland. In addition, large-scale navigational charts of the bay with the adjacent coasts, as well as the material previously obtained by specialists of the Maritime Academy during their field work on this section of the coast, have become an important information source.

Long-term hydrometeorological observations make it possible to create only a schematic picture of the process. Therefore, when preparing the article, a new approach to the study of the dynamics and ecology of sea coasts played a significant role. This refers to the use of modern hydrographic methods, when multibeam echo sounders (MBES) are used for hydroacoustic bottom surveying. Satellite positioning devices with portable computers are also connected to the new generation measuring equipment.

No less significant is the use of millimeter range radio waves, when the spatial picture of waves on the approaches to the coast is easily reproduced in a flat format on the circular view indicator (screen). Radar control makes it possible to easily determine the values of the wave periods, the phase velocities of the wave crests, as well as one of the essential characteristics of the wave field in shallow water - the orientation of wave fronts relative to the coast, i.e. the angles of wave approach to the coastline.

As a result, observing radar facilities are capable of displaying an image of an entire sector of the water surface on the screen with sufficient reliability at any time of the day. This makes it possible to track storm processes in real time in almost all details (with the exception of wave heights), i.e. it makes it possible to obtain a number of characteristics inherent in various phases of a storm: at the stages of its initiation, stabilization or decay [2, 3].

A significant amount of analyzed information was obtained from numerous open sources related to issues of hydrochemistry and environmental safety. All this was considered in relation to the conditions of the open sea coasts and, specifically, along the Gulf of Finland. Some heavy metals (HM) and oil products (OP) were used as indicator pollutants $[4,5,6]$.

Environmental monitoring of the entire eastern part of the Gulf of Finland showed a satisfactory state of the aquatic environment. The background content of heavy metals and oil products in water in relation to the activities of the fishery industries, according to existing materials, does not exceed the MPC today. However, in certain places, the level of harmful substances in natural waters is quite variable. The excess of the MPC for the content of heavy metals $(\mathrm{Pb}, \mathrm{Cu}, \mathrm{Zn}, \mathrm{Co})$ in the natural waters of the bay is characteristic of certain sections along the southern coast, such as the lower reaches of the Luga River (Luga 
Bay) or waste waters of the Leningrad NPP (Koporsky Bay). In addition, a significant segment of the northeastern part of the coast from the Lebyazhye village to the root of the CPS can be attributed here (the total indicator is given for the presence of cesium traces: $\mathrm{Zc}$ $=1.6-6.9$ ).

As for the bottom soils, the object of their study was the upper undisturbed layers of marine sediments, as well as samples from the lower horizons of the water column. The content of heavy metals in bottom sediments for individual elements increased in the following order: $\mathrm{Pb}(0.9 \%)<\mathrm{Cu}(0.22 \%)<\mathrm{Zn}(6.7 \%)<\mathrm{Cd}(19.6 \%)$. Cadmium and zinc are clearly distinguished as the most mobile elements. It is known that cadmium has a detrimental effect on aquatic vegetation, thereby reducing the oxygen index of the surrounding aquatic environment. Concerning zinc, it can be recalled that in Russia this chemical element is used as an additive in the manufacture of hull paints for ships. Hence, it is observed that it is widespread in the ground layers of domestic waters. In the United States, copper serves as a similar additive, the high content of which, in turn, is characteristic of the inlet waters of the North American coast.

The distribution of the total environmental risk for the individual named elements in the Gulf of Finland is as follows: $\mathrm{Zn}(3 \%)<\mathrm{Cu}(8 \%)<\mathrm{Pb}(14 \%)<\mathrm{Cd}(74 \%)$. It turns out that the greatest "contribution" to the current situation regarding this indicator is made by cadmium again. However, it is also necessary to take into account the negative effects of lead.

Similar conclusions about cadmium were made by foreign authors studying the bioavailability and toxicity of heavy metals in the groundwater layers of the Earth's water bodies in different parts of the globe [7, 8, 9]. In addition to cadmium, sometimes it is also mentioned about the accumulation of mercury $(\mathrm{Hg})$ in bottom sediments due to its toxicity. Besides mercury, nickel (Ni) deserves special attention due to its particularly high mobility $[10,11]$.

The most significant concentrations of cadmium $(1.2 \mu \mathrm{g} / 1$ with MPC of Cd equal to 1.0 $\mu \mathrm{g} / \mathrm{l})$ were recorded in the area of Bolshaya Izhora. Increased concentrations of heavy metals were also found in the Sisto-Palkino area (the coast of the Koporsky Bay), as well as in some other parts of the coastal zone within the Luga Bay and Koporsky Bay.

Another significant type of pollutants in this area are oil products. Based on materials from A. P. Karpinsky Russian Geological Research Institute (VSEGEI), tables of values of the content of hexane-soluble OP in natural waters and bottom sediments of the southern coast of the Gulf of Finland were compiled (Table 1,2).

The results of studies of the spatial distribution of OP in natural waters at the southern coast of the bay again showed the diversity of this type of pollution in the background content. The highest level of oil products in natural waters was found again in the Lebyazhye - B. Izhora section. Further, the average concentration of oil products and the proportion of anomalous samples goes down in the Luga and Koporsky bays. The same can be said for the gulf as a whole (Table 1).

Table 1. Characteristics of natural waters of the Gulf of Finland and its coastal zone by the content of hexane-soluble oil products $(\mathrm{OP})$ in them.

\begin{tabular}{|l|c|c|}
\hline \multicolumn{1}{|c|}{ Section name } & $\begin{array}{c}\text { Average harmonic content of } \\
\text { petroleum products, mg/l }\end{array}$ & $\begin{array}{c}\text { Percentage of samples with } \\
\text { OP content above the } \\
\text { regional background }\end{array}$ \\
\hline Water area & 0.011 & $52 \%$ \\
\hline $\begin{array}{l}\text { Watercourses in the } \\
\text { coastal zone outside } \\
\text { settlements }\end{array}$ & 0.010 & $18 \%$ \\
\hline Lebyazhye - B. Izhora & 0.023 & $85 \%$ \\
\hline Koporsky Bay & 0.013 & $60 \%$ \\
\hline
\end{tabular}




\begin{tabular}{|l|c|c|}
\hline Luga Bay & 0.023 & $76 \%$ \\
\hline Narva Bay & 0.029 & $33 \%$ \\
\hline $\begin{array}{l}\text { Gulf of Finland and its } \\
\text { coastal zone in general, } \\
\text { regional background }\end{array}$ & 0.015 & $62 \%$ \\
\hline
\end{tabular}

According to the state of bottom sediments and land areas adjacent to water, it can be argued about the content of hexane-soluble OPs that their background concentration here is $0.056 \mathrm{mg} / \mathrm{l}$. At the same time, the background value was exceeded by $68 \%$ of the number of available samples. Slightly higher than the general background, the average harmonic content of oil products in sediments was revealed again in the Lebyazhye - B. Izhora section (Table 2).

Table 2. Characteristics of modern bottom sediments in the soils of the Gulf of Finland by the content of hexane-soluble oil products (OP) in them.

\begin{tabular}{|l|c|c|}
\hline \multicolumn{1}{|c|}{ Section name } & $\begin{array}{c}\text { Average harmonic } \\
\text { content of petroleum } \\
\text { products, mg/ }\end{array}$ & $\begin{array}{c}\text { Percentage of samples with OP } \\
\text { content above the regional } \\
\text { background }\end{array}$ \\
\hline Lebyazhye - B. Izhora & 0.072 & $80 \%$ \\
\hline Koporsky Bay & 0.046 & $44 \%$ \\
\hline Luga Bay & 0.028 & $19 \%$ \\
\hline Narva Bay & 0.029 & $33 \%$ \\
\hline $\begin{array}{l}\text { Gulf of Finland and its } \\
\text { coastal zone in general, } \\
\text { regional background }\end{array}$ & 0.056 & $68 \%$ \\
\hline
\end{tabular}

In the considered coastal area, as well as in the central part of the Gulf of Finland, the share of anomalous samples with an index higher than the regional background is more than $80 \%$. In other parts of the southern coast, the average harmonic content of this type of pollution does not exceed the values of the regional background. The share of abnormal samples is close to $50 \%$.

\section{Discussion}

Upon completion of the ecological testing of the studied water area, quite expected results were obtained. As expected, the zones of influence of multifunctional sea port complexes and places of actively developing transport and oil infrastructure, in particular, the port complex of Ust-Luga, turned out to be less successful. In addition to the Luga Bay, the Koporsky Bay can be added to areas of increased environmental risk. In such places with a characteristic weakened hydrological regime, bottom sediments are, as a rule, represented by a finely dispersed mass with high absorption properties. It is in the muddy-silty soils, in comparison with the gravel-sandy fractions, that high concentrations of harmful substances are most often found, which, in fact, is one of the reasons for the deterioration of environmental conditions in the named places.

As for the hydrological features along the southern contour of the coast, they are generally characterized by a cyclonic form of water movement inherent in all large water bodies of the northern hemisphere - along the perimeter, counterclockwise. Obeying this law, the main vector of currents along the southern coast is oriented from west to east. With weak reversible winds or in calm weather, from any point on the southern coast, one can observe a smooth drift of water masses in the direction from left to right (Fig. 1).

However, the dynamic characteristics of coastal waters at the southern coast as a whole start to become fundamentally more complicated during periods of a burst of wind activity. As already noted, the winds of the western and northern directions serve as effective winds 
for this coast. That is, the southern component attributed in this case to the coastal type of winds is of little significance in terms of the impact on coastal processes.

The most important part of the entire coast is the tip of Cape Pitkinen Nos. At this point, there is a divergence of a single wave front generated by the winds of the western half. The wave energy flux, which determines the further dynamics of the coast, is divided at this place into two components. The southern branch of the wave front is oriented towards the Narva Bay, forming an alongshore sediment flow there, feeding, in particular, the Estonian beaches with sandy material. Its second component, which is extremely important, serves as the beginning of the formation of the second branch of the flow of matter - to the east (Fig. 2).

The second branch, having rounded the top of the Kurgalsky Peninsula, spreads to the southeast, towards the Luga Bay. In the central section of the curved coastal contour, the overall picture of water exchange during a storm becomes much more complicated. Luga and Koporsky bays can be considered as separate water bodies with their own wave regime and with individual schemes of local storm flows (Fig. 2).

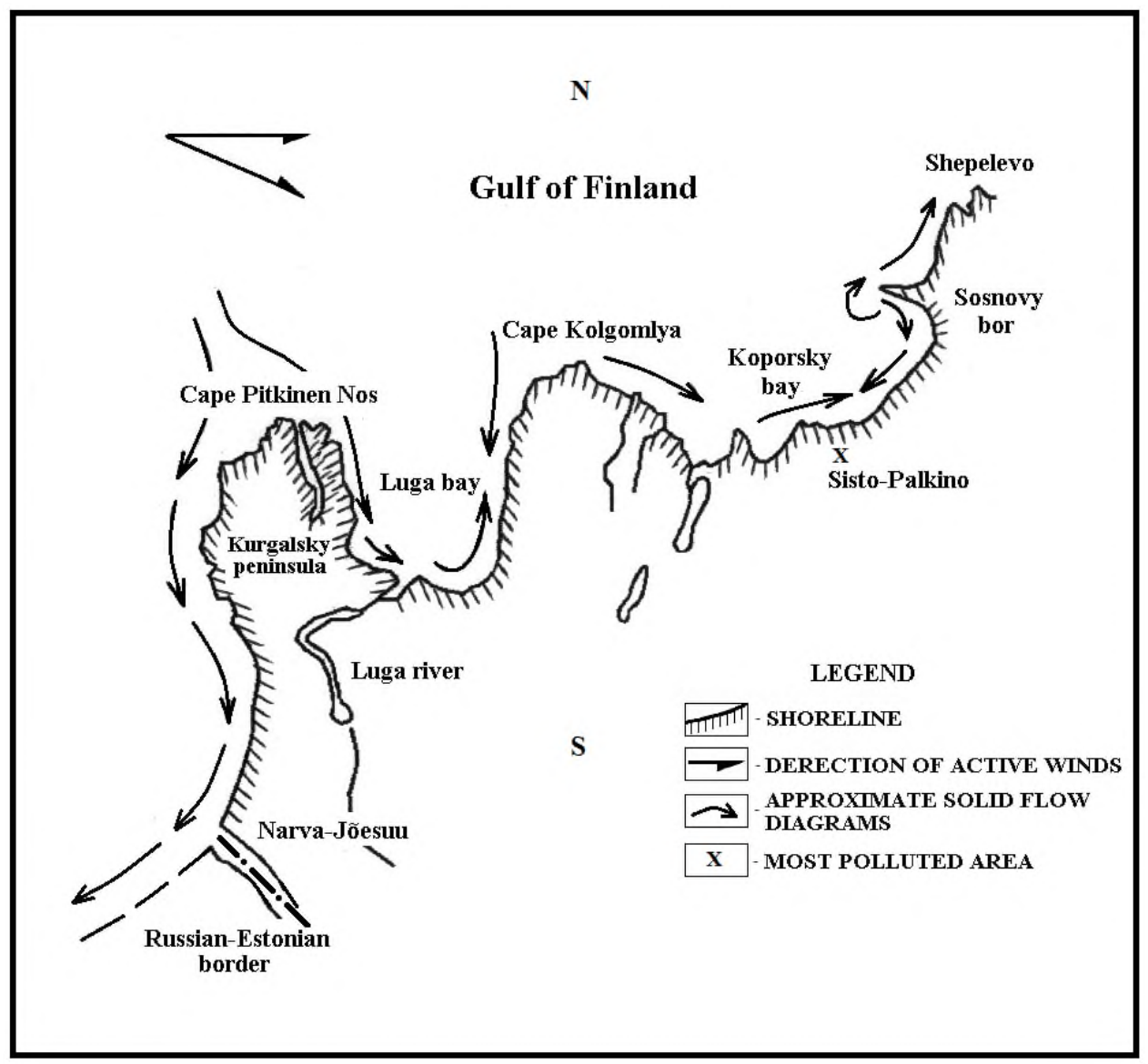

Fig. 2. Scheme of coastal storm streams in the western and central sections of the southern coast of the Gulf of Finland.

It is known that, as a rule, significant wave refraction is observed in the bay areas of the seas, i.e. distortion of wave fields. The latter strongly affects the nature and characteristics of local dynamics processes. According to the observations of V.P. Zenkovich, there are situations when a number of separate temporary streams of relatively small thickness are 
formed on the coasts of the bay type. Longinov, together with one of the authors of this article, noted that even under the conditions of a steady regime, the movement of matter (meaning - sediments) along the coast often has a pulsating, discontinuous character. On the way of such movement, landscape elements may come across, which divide the initially flat coast into sections with relatively independent regime characteristics.

Given this circumstance, in a specific case, uncertainty arises in the question of the reality of the existence of a single alongshore flow along the entire contour of the central part of the coast. This question remains open today.

One way or another, but in stormy situations, the pattern of water movement inherent in a real reservoir is supplemented by temporary storm flows, which are also oriented from west to east. Even V.P. Zenkovich drew attention to the fact that temporary storm currents can act in the coastal zones, the direction and speed of which are not related to the general circulation of water in this basin. These storm currents are temporary but very powerful sand transport agents. In a broader sense, it is more appropriate to use the words "flow of matter", which includes, in addition to muddy-silty suspension and entrained sandy mass, chemical solutions, emulsion inclusions, bulk material, drifting solid objects (such as quicksand, ice fragments), etc.

The third component of the southern coast (northeastern section) from Cape Shepelevsky to the Bolshaya Izhora settlement is geographically closest to St. Petersburg. Along the entire length, with the exception of the Black Lakhta bay, the coast in this place is rather monotonous. Calling him straightforward is not entirely correct. It rather falls under the category of undulating banks (Fig. 3).

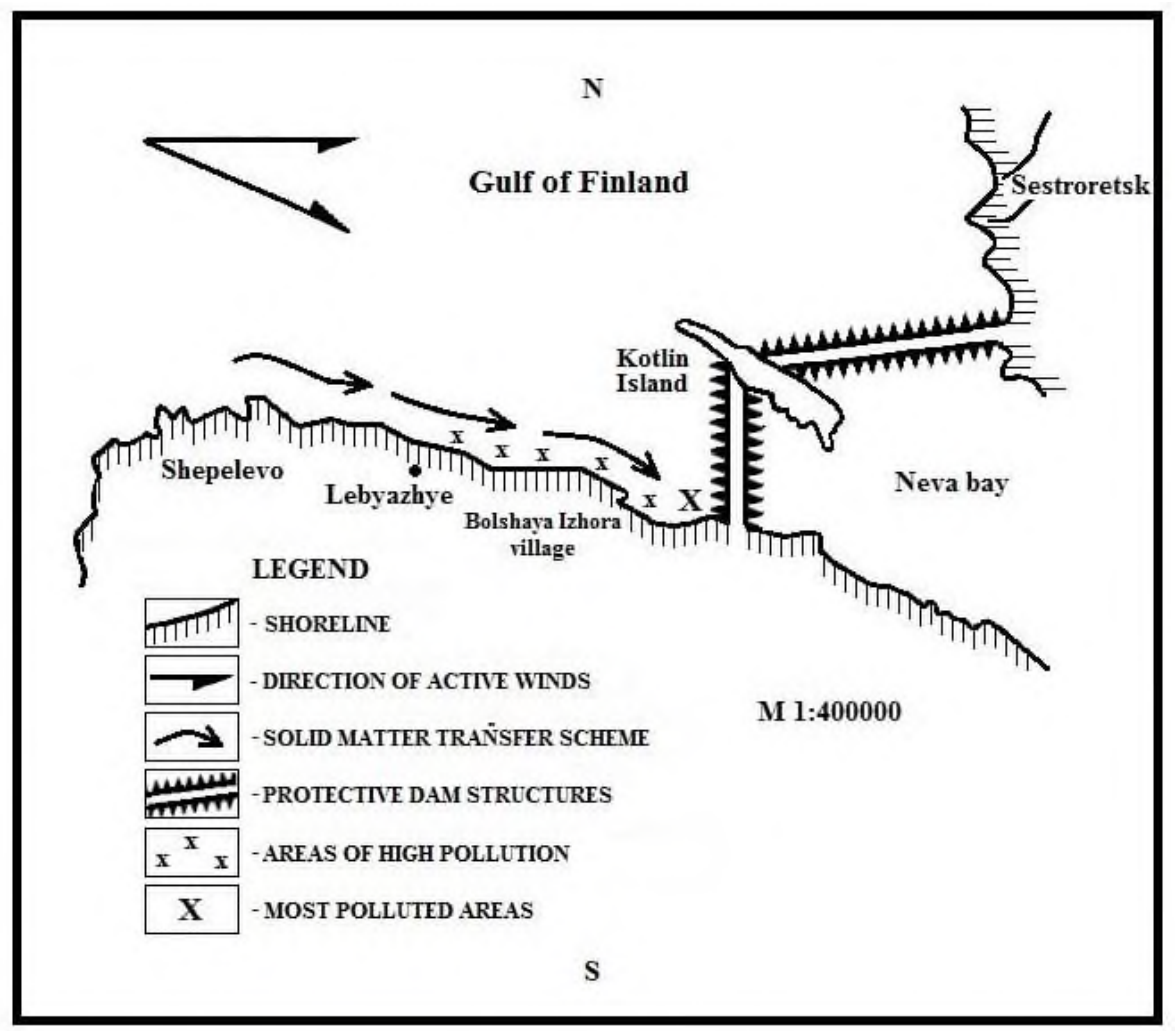

Fig. 3. Scheme of coastal storm flows in the northeastern section of the southern coast of the Gulf of Finland. 
In stormy conditions, judging by the pattern of the coastline, a single alongshore flow in the eastern direction should form here, on a fairly short section. Its end is the junction of the root part of the western wing of the CPS with the coast (Fig. 3).

Conditions in this area are far from favorable. First of all, this concerns sections of the coastline with obvious traces of abrasion, where from time to time there are places along the entire coastline with significant destruction of coastal slopes. At the same time, attention is drawn to the scarcity of beach areas with clear signs of a shortage of sand material. One of these indicators is the predominance of boulder and pebble deposits in certain places on the beaches $[12,13]$.

It would seem that belonging to the shores of the open type, i.e. under the direct influence of wave-breaking processes, the indicated interval of the coast should remain the most favorable in terms of sanitary and hygienic indicators. It is known that increased vortex formation of water masses, as a rule, promotes self-purification processes. However, it is here, from Shepelevo to CPS, that the greatest excess of MPC for the content of heavy metals was found in natural waters and soil. The same applies to the harmonic content of hexane-soluble oil products [14]. Some specialists interpret this situation as a consequence of large sedimentation processes, mainly due to the solid runoff of the Neva. It is difficult to agree with this, since when the Neva River flows into the bay of the same name, its dynamic axis deviates under the influence of the Coriolis force to the right, towards the Sestroretsk beaches. Thus, the presented concept does not fit into the general water exchange concept.

Most likely, the reasons for the unfavorable state of this coast lie elsewhere. No matter how complex the schemes of temporary currents, the general alongshore transit of matter here is one-sided - from west to east. Thus, the last section of the coast spatially coincides with the final phase of a single natural process.

With the construction of CPS, an additional barrier zone was formed here, which is confirmed by the data from the Bolshaya Izhora station. The erected dam blocked the existing route, forming a shadow corner at its base, i.e. an area of accumulation of harmful substances.

An equally significant reason for the negative character is the fact of the presence of an underwater formation on the final part of the considered coast, which is spread along the coastline and called the London Bar (Fig. 4). In the figure, this section of the water area is highlighted in a pale blue color. 


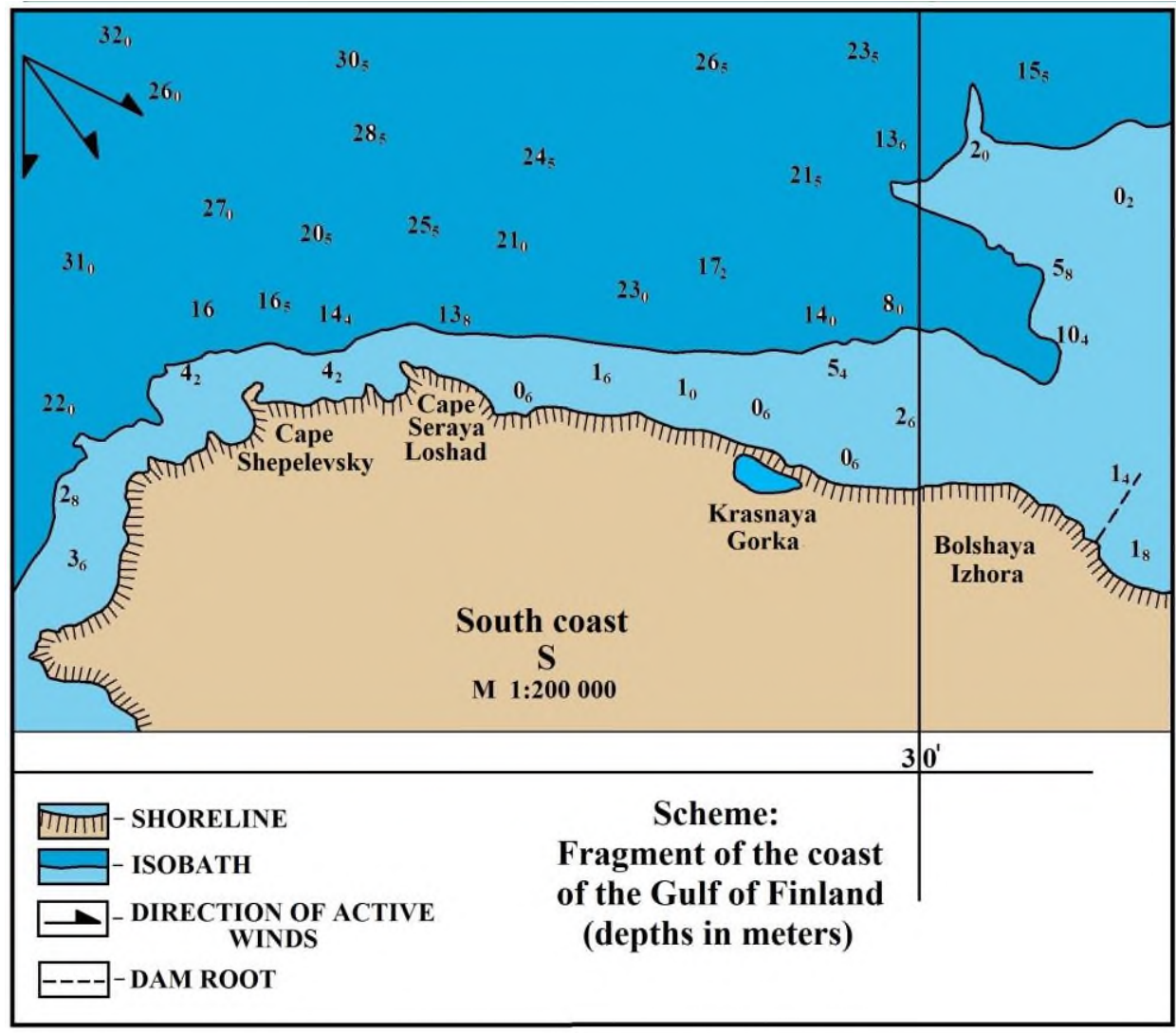

Fig. 4. Map of depths at the southern coast of the eastern part of the Gulf of Finland.

From the side of the sea, the coast was "locked" by the mentioned bar. Due to the shallows, the unfavorable ecological state of this section of the coast is caused by the excessively shallow coastal depths. Therefore, during periods of storm activity, the direct impact of the wind wave on the coast is blocked by the presence of this natural obstacle, thereby significantly reducing the wave-breaking effect. As a result, throughout the named coastal section, the ecological situation is more consistent with the conditions of the lagoon type, rather than the state of open sea coasts. Noteworthy is the widest size of the shallows in the section between Cape Seraya Loshad (Gray Horse) and CPS with especially low values of the bottom marks (depths).

Thus, a storm wave, overcoming a vast area of shallow water, loses a significant portion of its energy as it approaches the coast due to the braking effect of the shallow bottom. As a result, the wave mechanism loses the ability to perform one of the most important natural functions - self-cleaning (sanitation) of the ecosystem.

At the same time, with a sharp weakening of the wave impact, the remaining surf energy is not enough to participate in the beach-forming processes. A certain paradox arises: with an excessive accumulation of sand masses at the very edge of the coast, areas of the adjacent land experience a sharp shortage of beach material.

\section{Conclusion}

Summing up the results of the study of the southern coast of the Gulf of Finland in terms of environmental indicators, it is first of all necessary to highlight the places confined to the 
objects of active economic activity. Only anthropogenic processes are mentioned here. It is in such places that, as a rule, an increased level of pollution is observed. However, a coastal section with a length of about $25 \mathrm{~km}$ from Cape Seraya Loshad to the Complex of protective structures requires no less attention. Here it is appropriate to refer to the opinion of experts who assert that within this section, it is especially worth noting high concentrations of oil pollution in the immediate vicinity of the southern section of the dam. In this place, over the long-term observation period, there have never been any elevated concentrations of any chemical components. The appearance here of high concentrations of some pollutants in the sandy soil by 2003, according to some experts, may indicate manmade pollution, the source of which, most likely, was the construction of the Complex of protective structures. The question arises why there is no similar source of pollution on the opposite side of the structure, at the root of the northern wing of the dam, where similar construction work was also carried out.

Guided by the logic of the material presented in the article, the current situation can be explained by the following reasons.

Firstly, the specified place is geographically located in the zone where the alongshore flow acting in the one-way direction is at the stage of its completion. The construction of the dam created an additional barrier effect in this place. The resulting dead end zone must be kept under control, since the ecological situation here should only get worse over the years.

The second reason is associated with the presence of an extensive shallow along this coast, which prevents the impact of wave-cut processes on the coastal zone.

Earlier it was already noted that it was wrong to think that the drainage of the London bar could negatively affect the condition of the nearest southern shores. On the contrary, from an environmental standpoint, the elimination of a significant part of it should be seen as a step in the right direction. In such a situation, the natural conditions of the coast will dramatically change for the better. And the existing underwater formation, in turn, can be used as a source of sandy material. In terms of texture, along with sands, this deposit is formed by sandy clay and loam. Thus, its development is technically quite accessible with the use of modern dredging equipment, such as shallow draft dredgers, i.e. capable of operating in shallow water conditions.

From the point of view of improving the ecological situation in the region, the issue raised in the article is extremely important for both St. Petersburg and the Leningrad region, and requires a more in-depth and serious consideration $[15,16]$.

\section{References}

1. I.V. Kozhukhov, M.A. Spiridonov, Bulletin of the Admiral Makarov state University of the sea and river fleet 11.6(58), 1056-1069 (2019) DOI: 10.21821/2309-5180-201911-6-1056-1069

2. C.J. Daly, C. Winter, K.R. Bryan, Geomorphology 248, 252-263 (2015) DOI: 10.1016/j.geomorph.2015.07.040

3. M. Viška, T. Soomere, Baltica 26(2), 145 -156 (2013) DOI:10.5200/baltica.2013.26.15

4. B. Szymczycha, K.D. Kroeger, J. Pempkowiak, Marine Pollution Bulletin 109(1), 151 - 162 (2016) DOI: 10.1016/j.marpolbul.2016.06.008

5. A. Pejman, G.N. Bidendi, et al., Marine pollution bulletin 114(2), 881 - 887 (2017) DOI: 10.1016/j.marpolbul.2016.11.021

6. D. Depellegrin, P. Pereira, Marine Pollution Bulletin 102(1), 44 - 57 (2016) DOI: 10.1016/j.marpolbul.2015.12.005 
7. Ch.-Po Zhao, X.-J.L. Zhou, K. Dong, International journal of environment and pollution 61(1), 72 - 88 (2017) DOI: 10.1504/IJEP.2017.082700

8. K-L. Hutri, J. Mattila, T.T. Ikäheimonen, V-P. Vartti, Marine Pollution Bulletin 70(12), 210 - 218 (2013) DOI: 10.1016/j.marpolbul.2013.03.007

9. A. Giudici, J. Kalda, T. Soomere, Marine Pollution Bulletin 141, 573 - 585 (2019) DOI: 10.1016/j.marpolbul.2019.02.039

10. H. Vallius, Marine pollution bulletin 99(1-2), 250-255 (2015) DOI: 10.1016/j.marpolbul.2015.07.070

11. P.J. Vuorinen, O. Roots, M. Keinänen, Journal of Marine Systems 171, 141-150 (2017) DOI: 10.1016/j.jmarsys.2016.12.002

12. T. Wolski, B. Wiśniewski, Journal of Sea Research 159, 101890 (2020) DOI: 10.1016/j.seares.2020.101890

13. G. Uścinowicz, T. Szarafin, Ocean and Coastal Management 165, 258 - 267 (2018) DOI: 10.1016/j.ocecoaman.2018.08.033

14. V.M. Pitulko, V.V. Ivanova, V.V. Kulibaba, Ecological safety of marine natural and economic systems of the Russian Baltic States: monograph (INFRA-M, M., 2016) DOI: $10.12737 / 20232$

15. B. Viikmäe, T. Soomere, Journal of Marine Systems 129, 106 - 117 (2014) DOI: 10.1016/j.jmarsys.2013.06.014

16. L. Hakanson, Water Research 14(8), 975 - 1001 (1980) DOI: 10.1016/00431354(80)90143-8

17. G. Kozlov, et al. E3S Web of Conferences 175, 12015 (2020) do:10.1051/e3sconf/202017512015 